\title{
New technique to demonstrate corneal magnification using trypan blue in cataract surgery
}

\section{Nova técnica para demonstrar a magnificação corneana utilizando azul de tripan na cirurgia de catarata}

Frederico F. Marques' ${ }^{1}$, Daniela M.V. Marques ${ }^{1}$, Robert H. Osher ${ }^{2,3}$

\begin{abstract}
Purpose: To demonstrate the corneal magnification using trypan blue in cataract surgery. Methods: Eight eyes of eight patients undergoing phacoemulsification with an intraocular lens implantation were enrolled in this study. After staining the anterior capsule with Trypan Blue $0.1 \%$ and performing the capsulorhexis, the excised anterior capsule was placed on the corneal surface. By observing and measuring the relationship between the border of the excised anterior capsule and the intracameral capsulorhexis opening, the effect of corneal magnification was clearly demonstrated and calculated by linear method. Results The average magnification of the cornea was $20.88 \%$ using linear method with an average area magnification of $47.53 \%$. Conclusion: The capsulorhexis stained by trypan blue is useful to demonstrate the magnification provided by the cornea helping to design an intended opening size.
\end{abstract}

Keywords: Capsulorhexis; Phacoemulsification; Corneal magnification

\section{RESUMO}

Objetivo: Demonstrar a magnificação corneana utilizando o azul de tripan na cirurgia de catarata. Métodos: Oito olhos de oito pacientes submetidos à facoemulsificação com implante de lente intraocular foram envolvidos neste estudo. Após corar a cápsula anterior do cristalino com azul de tripan $0,1 \%$ e realizar a capsulotomia circular contínua, a cápsula excisada foi colocada sobre a superfície corneana. Após observar e aferir a relação entre a borda da cápsula anterior excisada e a abertura da cápsula intracameral, o efeito da magnificação corneana foi claramente demonstrada e calculada através do método linear. Resultados: A média estimada da magnificação corneana foi de 20,88\% com uma média de magnificação de área de 47,53\%. Conclusão: A capsulorrexis corada pelo azul de tripan é útil na demonstração da magnificação corneana, auxiliando assim na correta confecção do seu tamanho.

Descritores: Capsulorrexis; Facoemulsificação; Magnificação corneana

\footnotetext{
${ }^{1}$ MD,Department of Ophthalmology, Faculdade de Medicina do ABC - FMABC - Santo André - (SP), Brazil;

${ }^{2} \mathrm{MD}$, Cincinnati Eye Institute, Cincinnati, Ohio;

${ }^{3} \mathrm{MD}$, Department of Ophthalmology, University of Cincinnati College of Medicine - Ohio.
}

The autors received no public or private financial support

Recebido para publicação em: 20/10/2010 - Aceito para publicação em 14/11/2011 


\section{INTRODUCTION}

$\mathbf{T}$ The size of the capsulorhexis plays an important role in contemporary cataract surgery. Yet the actual size of the capsular opening is difficult to appreciate because of corneal magnification. The diameter of the excised anterior capsule with relation to the capsular opening can vividly demonstrate corneal magnification and its effect can be estimated. The purpose of this paper is to demonstrate the magnification provided by the cornea in cataract surgery using trypan blue as an important tool to establish this relationship.

\section{Methods}

Eight patients with either a white or brunescent cataract underwent phacoemulsification with implantation of an acrylic intraocular lens. The anterior capsule was stained by a "3-step technique" using viscoadaptive viscoelastic solution (Healon5®), balanced salt solution, and Trypan Blue $0.1 \%$, using a method that was accepted for publication ${ }^{(1)}$. The excised anterior capsule was retrieved and placed upon the corneal surface oriented to correspond to the remaining opening. The horizontal diameter of both the externalized anterior capsule and the intracameral margins of the capsular opening were estimated using a same caliper with a millimeter scale on the corneal surface in all cases. The measures were repeated three times. In order to obtain a more precise measurement by eliminating parallax, the image through a Sony 3-chip model 760 camera was recorded on videotape from which a $5 \times 7-$ inch photograph was printed. A standard millimeter ruler was used to confirm the previous intraoperative measurements. Magnification was assessed by the linear method (described above) and its area $\left(\mathrm{A}=\pi \cdot \mathrm{r}^{2}\right)$ was also recorded.

\section{Results}

The diameter of the excised anterior capsule and the intracameral diameter of the capsulorhexis margins as viewed through the cornea were analyzed using a linear method described above and its area using the circle area $\left(\mathrm{A}=\pi \cdot \mathrm{r}^{2}\right)$.

The average excised anterior capsule measured $4.75 \mathrm{~mm}$ (range 4.0 to $5.5 \mathrm{~mm}$ ); the average continuous circular capsulotomy (CCC) measured $5.78 \mathrm{~mm}$ (range 5.0 to $6.8 \mathrm{~mm}$ ) and the average corneal magnification provided by the linear method was $20.88 \%$ (range 12.96

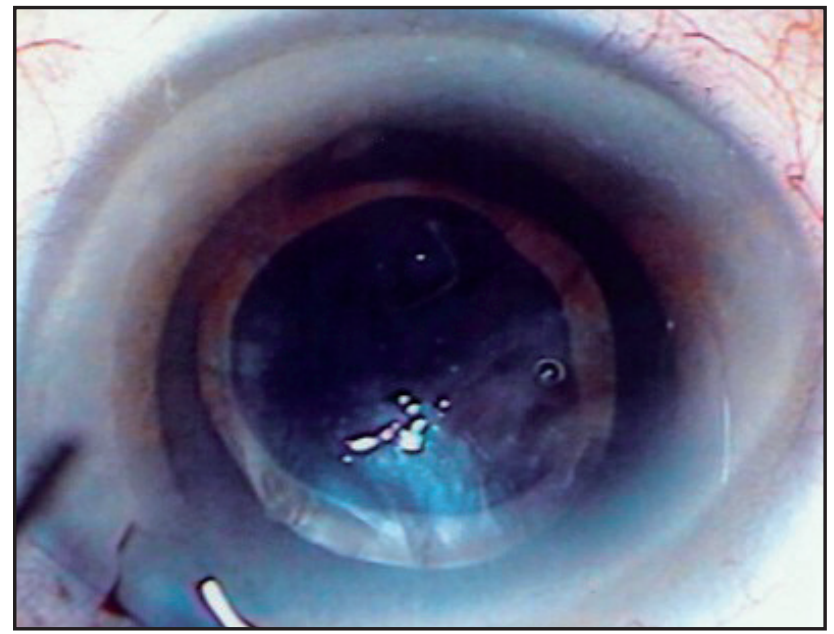

Figure 1: The anterior lens capsule stained by trypan blue $0.1 \%$ is unfolded and placed onto the corneal surface coaxial with the microscope

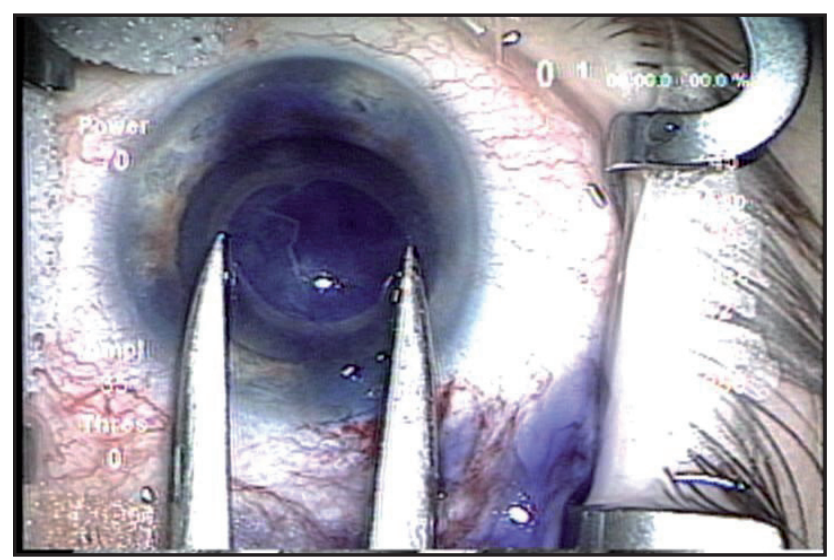

Figure 2: The excised anterior capsule placed onto the corneal surface measured with an $\mathrm{mm}$. caliper

Table 1

\section{Corneal magnification using linear method}

\begin{tabular}{cccc}
\hline $\begin{array}{c}\text { Case } \\
\text { Number }\end{array}$ & $\begin{array}{c}\text { Excised Anterior } \\
\text { Capsule Diameter } \\
(\mathbf{m m})\end{array}$ & $\begin{array}{c}\text { CCC } \\
\text { diameter } \\
(\mathbf{m m})\end{array}$ & $\begin{array}{c}\text { Corneal } \\
\text { Magnification } \\
(\mathbf{\%})\end{array}$ \\
\hline 1 & 5.5 & 6.8 & 23.64 \\
2 & 5.4 & 6.1 & 12.96 \\
3 & 4.8 & 5.7 & 18.75 \\
4 & 5.1 & 6.0 & 17.64 \\
5 & 4.1 & 5.2 & 26.83 \\
6 & 4.0 & 5.0 & 25.00 \\
7 & 4.5 & 5.5 & 22.23 \\
8 & 5.0 & 6.0 & 20.00 \\
Average & $\mathbf{4 . 7 5}$ & $\mathbf{5 . 7 8}$ & $\mathbf{2 0 . 8 8}$ \\
\hline
\end{tabular}


to $26.83 \%$ ) as showed in table 1 .

The average excised anterior capsule area measured $6 \pi \mathrm{mm}$ (range 4.0 to $7.65 \pi \mathrm{mm}$ ); the average CCC area measured $8.56 \pi \mathrm{mm}$ (range 6.25 to $11.56 \pi$ $\mathrm{mm}$ ) and the average corneal magnification area provided was $47.53 \%$ (range 27.6 to $60.85 \%$ ).

\section{Discussion}

Much has been published on the ideal size of the capsulorhexis with respect to sealing the optic in order to reduce the risk of posterior capsular opacification ${ }^{(2)}$. But because the rhexis is performed before the optic is implanted, the surgeon must guess the size of the capsulotomy that will be ideal. This presents not only a technical challenge differing from capsule to capsule, but the surgeon's perception changes when either the pupil size or the size of the anterior segment varies, particularly in cases where the pupil is wide dilated as in highly myopic eyes or in megalophthalmos. Corneal marking with a fixed gauge and capsular marking with an intraocular ruler have been recently described ${ }^{(3,4)}$. Theoretically, the surgeon could precisely mark the cornea prior to performing the capsulotomy, if the corneal magnification was known. Yet the attention directed to corneal magnification is sparse, both from the podium and in the literature.

The image magnification has been studied in refractive surgery to analyze the changes in specular microscopy, the retinal image size, and to evaluate the corneal reflex test in spectacle wearers ${ }^{(5-7)}$. In a published correspondence, Waltz and Rubin discussed the relationship between the size of the anterior capsule and corneal magnification ${ }^{(8)}$. The authors suggested that cornea magnifies the anterior capsule approximately 1.15 times, which is very similar to our findings using the linear method (1.21 times).

With the introduction of the capsular dyes, we realized that an opportunity existed to clearly demonstrate the effect of corneal magnification. It was not our purpose to advocate using capsular dyes, although we strongly believe that there is added safety when it is difficult to visualize the capsulorhexis ${ }^{(9,10)}$. Nor was it our purpose to propose that the ideal size of the rhexis would be precisely marked prior to performing the CCC, although it is possible given the average magnification of $20 \%$ calculated in our small series. In fact, we have not studied the influence that corneal curvature, pachymetry, anterior chamber depth have on magnification. The capsular opening is another point to be considered since the capsule can be stretched by the zonules forces after been incised increasing its size, although it is known that this factor is important in younger patient due its higher capsule elasticity and might be clinically not significant in adult capsules.

What we have tried to accomplish is to remind the surgeon that there is an impressive difference between what he or she perceives versus what is the actual size of the capsulorhexis. Corneal magnification may prove even more important as microsurgical techniques and newer IOL technologies evolve.

\section{Conclusion}

The corneal magnification can be clearly analyzed in cataract surgery using capsular dye to stain the anterior lens capsule, visualize the externalized anterior capsule and the capsular opening edge and evaluate them.

\section{REFERENCES}

1. Marques DM, Marques FF, Osher RH. Three-step technique for staining the anterior lens capsule with indocyanine green or trypan blue. J Cataract Refract Surg. 2004;30(1): 13-6. Comment in: J Cataract Refract Surg. 2004;30(12):2462; author reply 2462. J Cataract Refract Surg. 2005;31(2):259-60.

2. Ravalico G, Tognetto D, Palomba M, Busatto P, Baccara F. Capsulorhexis size and posterior capsule opacification. J Cataract Refract Surg. 1996;22(1):98-103.

3. Wallace RB 3rd. Capsulotomy diameter mark. J Cataract Refract Surg. 2003;29(10):1866-8. Comment in: J Cataract Refract Surg. 2004;30(10):2031-2.

4. Fogla R, Rao SK. Device for intraoperative measurement of capsulorhexis dimensions. J Cataract Refract Surg. 2003;29(8):1643-4

5. Isager P, Hjortdal JO, Ehlers N. Magnification changes in specular microscopy after corneal refractive surgery. Acta Ophthalmol Scand. 1999;77(4):391-3.

6. Applegate RA, Howland HC. Magnification and visual acuity in refractive surgery. Arch Ophthalmol. 1993;111(10):1335-42.

7. Hatsukawa Y, Koike H, Sugimoto S, Kasai K, Fells P. Mathematical analysis and experiment on the corneal reflex test in spectacle wearers. Br J Ophthalmol. 1994;78(9):707-13

8. Waltz KL, Rubin ML. Capsulorhexis and corneal magnification. Arch Ophthalmol. 1992;110(2):170. Comment on: Arch Ophthalmol. 1991;109(5):642-7.

9. de Waard PW, Budo CJ, Melles GR. Trypan blue capsular staining to "find" the leading edge of a "lost" capsulorhexis. Am J Ophthalmol. 2002;134(2):271-2.

10. Osher RH. Surgical triumph over a variety of challenging cataracts. Binkhorst Lecture, 2000.

\section{Address correspondence: \\ Frederico F. Marques, MD \\ Rua Indiana, $n^{\circ} 527$ - apto. 81 \\ CEP 04562-000 - São Paulo - (SP), Brazil \\ Phone: (11) 5677-3513 - Fax: (11) 5677-3513}

